\title{
Worry as a window into the lives of people who use injection drugs:
} a factor analysis approach Heidi Exner ${ }^{1}$, Erin K Gibson ${ }^{1}$, Ryan Stone ${ }^{2}$, Jennifer Lindquist ${ }^{2}$, Laura Cowen ${ }^{2}$ and Eric A Roth*3

Address: ${ }^{1}$ AIDS Vancouver Island, 1601 Blanshard Avenue, Victoria, British Columbia, V8W 2J5, Canada, ${ }^{2}$ Department of Mathematics and Statistics, PO BOX 3060 STN CSC, Victoria, British Columbia, V8W 3R4, Canada and ${ }^{3}$ Department of Anthropology, University of Victoria, PO Box 3050, STN CSC, Victoria, British Columbia, V8W 3P5, Canada

Email: Heidi Exner - Heidi.Exner@avi.org; Erin K Gibson - erinkgibson@gmail.com; Ryan Stone - ryestone@uvic.ca; Jennifer Lindquist - jenl@uvic.ca; Laura Cowen - lcowen@uvic.ca; Eric A Roth* - ericroth@uvic.ca

* Corresponding author

Published: 29 July 2009

Harm Reduction Journal 2009, 6:20 doi:10.1/86/1477-75/7-6-20
Received: 13 February 2009

Accepted: 29 July 2009

This article is available from: http://www.harmreductionjournal.com/content/6/1/20

(c) 2009 Exner et al; licensee BioMed Central Ltd.

This is an Open Access article distributed under the terms of the Creative Commons Attribution License (http://creativecommons.org/licenses/by/2.0), which permits unrestricted use, distribution, and reproduction in any medium, provided the original work is properly cited.

\begin{abstract}
Background: The concept of risk dominates the HIV/AIDS literature pertaining to People Who Use Injection Drugs (PWUID). In contrast the associated concept of worry is infrequently applied, even though it can produce important perspectives of PWUID's lives. This study asked a sample (n $=105$ ) of PWUID enrolled in a Victoria, British Columbia needle exchange program to evaluate their degree of worry about fourteen factors they may encounter in their daily lives.
\end{abstract}

Methods: Exploratory factor analysis was used to analyze their responses.

Results: Factor analysis delineated three factors: I) overall personal security, 2) injection drug usespecific risks including overdosing and vein collapse and, 3) contracting infectious diseases associated with injection drug use (e.g. HIV/AIDS and hepatitis C).

Conclusion: PWUID in this study not only worry about HIVIAIDS but also about stressful factors in their daily life which have been linked to both increased HIVIAIDS risk behaviour and decreased anti-retroviral treatment adherence. The importance PWUID give to this broad range of worry/ concerns emphasizes the need to place HIVIAIDS intervention, education, and treatment programs within a broader harm-reduction framework that incorporates their perspectives on both worry and risk.

\section{Background}

Injection drug use is a driving force in historic HIV epidemics in North America and emerging epidemics in Asia and Eastern Europe [1], and is the world-wide leading cause of hepatitis C infection [2]. As a result the public health and epidemiological literature on People Who Use Injection Drugs (PWUID) [3] is dominated by the concept of "risk", associated largely with the sharing of injection drug equipment. Applications of the concept of risk to PWUID originated with seminal studies on disease transmission parameters $[4,5]$, evolved to consider risk networks $[6,7]$, and presently focus on risk environments [8] and the structural production of risk [9].

In contrast to this long-standing concern with the concept of risk there has been relatively little development of a 
related concept, that of worry, in the HIV/AIDS literature. A notable exception is Smith and Watkins' $[10,11]$ substitution of "worry" about contracting HIV/AIDS in place of "risk of HIV/AIDS". In doing so they argue that worry is an important concept since, "worry is universally experienced and more emotionally based than perceived risk, respondents may have less difficultly understanding the concept of worry and articulating their levels of worry than describing their perceived risk" [10:72]. To this we add that consideration of what people worry about can help identify what individuals and/or groups perceive as actually constituting risks, since risk is now assumed to be socially constructed [9]. From this perspective we can define worry as the recognition of risk. As such consideration of what people worry about has the potential to provide important "windows" into their lives by identifying the risks and challenges they face. This is exemplified by Busza's [12] study of worry patterns for Vietnamese sex workers in Cambodia, which revealed worry about HIV/ AIDS nested within broader frameworks encompassing the need to provide funds for extended families in Vietnam, issues of police harassment, and demanding brothel owners.

For PWUID the importance of considering broader factors of concern was highlighted by Mizuno et al. [13] who asked HIV-seropositive PWUID to rank order their "life priorities" from a list of seven items including HIV, housing, having money, food, being able to work, childcare, and safety from violence. In their sample of 161 individuals only $37 \%$ ranked HIV as a top priority, while nearly half ranked HIV as their fourth priority or lower. Similarly Brogly et al. [14] asked Montreal PWUID to choose five cards representing what they perceived as the most important factors in their quality of life from a group of seventeen cards including HIV/AIDS treatment, drug treatment, health, being useful, education, feeling good about yourself, independence and free choice, spirituality, friends, family, partnership, sex, housing, money, resources leisure activities, and drugs. From this list the most frequently chosen factors were housing, health, money, spirituality, family, and feeling good about yourself. Only $13 \%$ of participants included HIV/AIDS treatment as an important factor, and this factor ranked a lowly twelfth out of the possible seventeen items.

This recognition of worries in addition to HIV/AIDS infection or treatment is important because both ethnographic studies [15] and health surveys [16] report on the chaotic nature of PWUID's lives, with homelessness, stigma, and lack of resources associated with high-risk behaviours ranging from sharing injection drug paraphernalia to survival sex, while simultaneously acting as barriers to HIV/ AIDS treatment [17]. In the present paper we analyze responses to a survey questionnaire to delineate worry patterns for PWUID enrolled in a long-established needle exchange program in Victoria, British Columbia in order to gain a broader understanding of what they identify as risk and worry about in their everyday lives.

\section{Methods}

Data for this study were generated by a survey of AIDS Vancouver Island's Street Outreach Services (AVI-SOS) Needle Exchange Program clientele. Conducted in AprilMay/2008 the survey represented a collaborative research project between members of AIDS Vancouver Island and the University of Victoria designed to address the issue of continued injection drug equipment sharing among needle exchange clientele [18]. AIDS Vancouver Island has a long-running Street Outreach Services (AVI-SOS) Needle Exchange Program. Established in the early 1990s, this service exchanges syringes throughout Vancouver Island. In June 2008 the service was evicted from its fixed Victoria site as a result of a neighbourhood association lawsuit and now operates a mobile needle exchange service in Victoria.

For the present study, eligibility criteria limited participation to persons aged eighteen and over who had injected illicit drugs within the past four months and who were active on the AVI-SOS registry. This registry contains datespecific records of all needle exchanges listed by clients' unique codes. The University of Victoria's Human Research Ethics Board reviewed and approved the survey instrument (Human Subjects' Certificate 08-277). Participants were paid a $\$ 20$ honorarium for participating in the survey interview, which took less than an hour to administer. The survey included sections pertaining to: 1) basic demographic and educational history, 2) substance use history, 3) current injection practices, 4) egocentric risk networks, 5) worry factors and, 6) drug sharing scenarios.

In total 105 AVI-SOS clientele completed the survey questionnaire. Descriptive statistics for this sample are presented in Tables 1 and 2 . These indicate a predominantly male $(70 \%)$, White $(77 \%)$, and older (mean age $>40.0$ years) sample. Clientele interviewed were characterized by both a long Victorian residency (mean years in Victoria $>17$ years) and a lengthy affiliation with the needle exchange (mean time period needle exchange client $>7$ years). Despite fairly high levels of formal education and literacy, with almost one-half (48\%) completing high school, slightly more than half the interviewees were homeless at the time of the survey (average number of places slept in last week $=2.5$ ) and another $10 \%$ were living in shelters. Overall the sample consisted of older, street-entrenched injection drug users with both a long Victoria residence, and a lengthy association with the AVISOS needle exchange program. 
Table I: AVI-SOS Clientele descriptive statistics for 105 individuals

\begin{tabular}{lrr}
\hline Variable & N & $\%$ \\
\hline Gender & & \\
Male & 74 & 70 \\
Female & 30 & 29 \\
Transgender & I & I \\
Ethnicity & & \\
White & 81 & 77 \\
Black & 3 & 3 \\
Hispanic & 0 & 0 \\
Aboriginal & 15 & 14 \\
Metis & 6 & 6 \\
Education & & \\
Grades I-8 & 16 & 15 \\
Attended High School & 39 & 37 \\
Graduated High School & 26 & 25 \\
Post-Secondary & 24 & 23 \\
Housing Situation & & \\
Own/Rent & 41 & 39 \\
Subsidized Housing & 10 & 10 \\
Homeless & 54 & 51 \\
\hline
\end{tabular}

To investigate worry patterns survey participants scored 14 items on a five-point scale measuring how frequently they worry about each item, with the scale being: $1=$ Never, 2 = Once a month, 3 = Weekly, $4=$ Daily, $5=$ All the time. While response rates to sections within the total survey varied, for example over $10 \%$ chose not to complete the network questions, all 105 participants completed this section which was written by AVI-SOS staff in collaboration with needle exchange clientele and pretested to ensure that questions representing risks and challenges Victoria PWUID face daily were included, and that question wording and terminology were clear. In the actual questionnaire administration, both individual clients and interviewers had a copy of the questionnaire and went through each section together to ensure mutual understanding of the instrument's questions.

From discussions with AVI staff and needle exchange clientele prior to administering the questionnaire the 14 items in the worry section were thought to represent three areas of risk and worry for PWUID. These were:

1: Overall Security - this included worry about food and housing as well as personal safety, denoted on the ques-

Table 2: Sample size, mean, standard deviation, and range for AVI-SOS clientele descriptive variables

\begin{tabular}{lcrrr}
\hline Variable & N & Mean & SD & Range \\
\hline Age & 105 & 41.6 & 8.5 & $19-6 \mid$ \\
Years lived in Victoria & 103 & 17.3 & 13.4 & $0-55$ \\
Number of places slept last week & 105 & 2.5 & 2.0 & $1-7$ \\
Years needle exchange client & 105 & 7.2 & 5.3 & $0-19$
\end{tabular}

tionnaire as the following items (item number in parentheses): Having a place to stay (8), Able to get food (10), Being robbed (7), Being assaulted (9), Being farmed (robbed while sleeping or high) by your peers (11) and Police arrest (or being jacked up by police) (2).

2: Injection Drug Use-Specific Worries - included here were: Overdosing (1), Vein damage (6), Missing your smash (or vein) (13), Police confiscating syringes (12) and, Getting clean needles (14).

3: Infectious Disease Worries - these include worry about contracting HIV/AIDS, (3), Hepatitis C Infection (4) and Sexually Transmitted Infections (5).

To assess whether the survey participants also viewed these multiple items in the same perspective we used the SAS $^{\circledast}$ (Version 9.13) PROC FACTOR sub-routine to perform an exploratory factor analysis on responses to the worry questions. Factor analysis is a data reduction statistical technique designed to delineate a hypothesized underlying structure of large data sets represented by numerous variables [19]. While our data set cannot be considered large, it does meet an important guideline for factor analysis; that the minimum number of subjects in a sample be either 100 subjects or 5 times the number of variables being analyzed, whichever is larger [20:73]. In our sample 105 participants responded to 14 variables, thus qualifying on both criteria.

Factors are assumed responsible for the covariation between two or more observed variables. Based on either correlation or covariance matrices, factor analysis extracts factors representing shared variance. In this paper, factors were extracted using the maximum likelihood option contained within PROC FACTOR, which permits hypothesis testing for the best number of factors to be retained [20]. Extracted factors were then rotated, that is, a linear transformation was performed on the factor solution for easier interpretation, via the PROMAX option in SAS, rendering the extracted factors correlated or "oblique". Individual variables were considered to "strongly load" on each factor if they possessed factor loading scores equal to or above 0.40 [19:29]. Variables which did not achieve this level (known as low-loading) were removed from subsequent analysis.

To determine the number of factors to be retained in the model a scree test or plot depicting each of the variables as a separate factor with respect to its corresponding eigenvalue (interpreted as the amount of variance accounted for by each factor) was constructed. The point at which the slope of the plot changes from a rapid to a slow decline is the cut-off for the number of factors to be retained. This point separates factors with large eigenvalues from those with relatively small eigenvalues [21]. In addition, as max- 
imum likelihood techniques were used to estimate the factor coefficients, a Chi-square test of the hypothesis that $\mathrm{k}$ factors are sufficient was performed.

\section{Results}

\section{Univariate results and reliability estimates}

To first measure the degree of worry recorded for each variable and to determine if they are associated, we calculated their means and standard deviations. These results are presented in Table 3 with the individual variables placed according to their proposed factor. As seen here there was a wide range exhibited in the mean values for each variable, ranging from the highest value (mean $=3.11$ ) associated with having a place to stay, to the lowest values recorded for being able to obtain clean needles (mean $=$ $1.72)$ and worry about police arrest (mean $=1.76)$. Worry about HIV/AIDS had the fourth highest ranking (mean = 2.84 ) below only worry about having a place to stay, being robbed $($ mean $=2.91)$, and contracting hepatitis $\mathrm{C}$ $($ mean $=2.89)$.

Also shown in Table 3 is a measure of inter-variable reliability known as Cronbach's alpha, which denotes how well the variables in each proposed factor are related. A

Table 3: Descriptive statistics for individual variables and Cronbach's alpha for each proposed factor

\begin{tabular}{|c|c|c|}
\hline Overall Security & & \\
\hline Variable & Mean & SD \\
\hline Having a Place to Stay & 3.11 & 1.76 \\
\hline Able to Get Food & 2.01 & 1.41 \\
\hline Being Robbed & 2.91 & 1.63 \\
\hline Being Assaulted & 2.51 & 1.56 \\
\hline Being Farmed & 2.68 & 1.66 \\
\hline Being Arrested & 2.76 & 1.59 \\
\hline \multicolumn{3}{|c|}{ Injection Drug Use-Specific Worries ${ }^{2}$} \\
\hline Variable & Mean & SD \\
\hline Overdosing & 2.04 & 1.34 \\
\hline Vein Damage & 2.65 & 1.57 \\
\hline Missing Your Smash & 2.56 & 1.70 \\
\hline Police Confiscating Needles & 1.76 & 1.44 \\
\hline Getting Clean Needles & 1.72 & 0.45 \\
\hline \multicolumn{3}{|c|}{ Infectious Disease Worries ${ }^{3}$} \\
\hline Variable & Mean & SD \\
\hline HIVIAIDS & 2.84 & 1.69 \\
\hline Hepatitis C Infection & 2.89 & 1.71 \\
\hline STIs & 2.11 & 1.50 \\
\hline
\end{tabular}

${ }^{\mathrm{I}} \alpha=0.75,{ }^{2} \alpha=0.7 \mathrm{I},{ }^{3} \alpha=0.74$ commonly applied rule of thumb is that alpha levels should equal or exceed 0.70. As shown in Table 3 this level is met for all three of the proposed factors.

\section{Factor analysis}

Factor analysis proceeded in a two-step manner. First, all fourteen variables were included in the analysis, and the results examined for low-loading variables. Two variables, FARMED and ARREST (Questions 3 and 6 respectively) did not load strongly on any factor. Accordingly, in the second step these variables were removed and the analysis repeated. For this second run the corresponding scree plot was constructed. This revealed a steep drop-off in eigenvalues after the first factor, which had an eigenvalue of 5.14. The second factor featured an eigenvalue of 2.02, while the third factor had an eigenvalue of 0.97 . Further, there was not enough evidence to reject the hypothesis that 3 factors are sufficient $\left(\mathrm{X}_{33}=33.4\right.$, $\mathrm{p}$-value $\left.=0.45\right)$. Based on the scree plot and the chi-square test, 3 factors were retained in the model.

Examination of the variable loadings, representing standardized regression coefficients, for each of the three factors is shown in Table 4. These data support our initial supposition of three distinct factors pertaining to: 1) worry about overall personal security, 2) specific worries associated with injection drug use and, 3) worry about contracting infectious diseases associated with injection drug use. The first factor, worry about overall security accounts for over $60 \%$ of the total variance and is represented by four manifest variables, being robbed (ROBBED), assaulted (MUGGED), having a place to stay (PLACE) and finding food (FOOD). The second factor contains five variables, worry about overdosing (OD), vein collapse (VEINS), getting clean needles (CLEAN), police taking needles (TAKE) and missing your smash (SMASH), and contributes another $24 \%$ of the total variance. The third factor includes the variables relating to worry about contracting

Table 4: Rotated factor pattern and standardized regression coefficients for the 3 factor model.

\begin{tabular}{cccc}
\hline Variable & Factor I & Factor 2 & Factor 3 \\
\hline Overdose & 0.00 & $\mathbf{0 . 4 1}$ & 0.17 \\
HIV & -0.18 & 0.21 & $\mathbf{0 . 6 7}$ \\
HCV & 0.10 & -0.14 & $\mathbf{0 . 8 7}$ \\
STI & 0.09 & 0.16 & $\mathbf{0 . 4 7}$ \\
Veins & 0.11 & $\mathbf{0 . 4 2}$ & 0.28 \\
Robbed & $\mathbf{0 . 7 0}$ & -0.01 & -0.06 \\
Place & $\mathbf{0 . 6 9}$ & 0.01 & -0.02 \\
Mugged & $\mathbf{0 . 7 6}$ & -0.03 & -0.08 \\
Food & $\mathbf{0 . 5 2}$ & 0.08 & 0.03 \\
Take & 0.01 & $\mathbf{0 . 4 7}$ & 0.08 \\
Smash & 0.10 & $\mathbf{0 . 7 4}$ & -0.14 \\
Clean & 0.08 & $\mathbf{0 . 5 5}$ & 0.06 \\
\hline
\end{tabular}

Coefficients that loaded on a factor $(\geq 0.40)$ are in bold 
HIV/AIDS, hepatitis C (HCV), and sexually transmitted infections (STIs) contributed the remaining $15 \%$ of variation.

\section{Discussion}

This paper performed an exploratory factor analysis on data pertaining to a broad array of possible worries thought to characterize the daily life of People Who Use Injection Drugs currently enrolled in a needle exchange program administered by AIDS Vancouver Island, in Victoria, British Columbia, Canada. In doing so it was proposed that three common factors representing worry about overall personal security, health concerns specific to injection drug use, and contracting HIV, HCV, and STIs would be delineated. Exploratory factor analysis indicated that the data did indeed contain these three specific factors. Equally important, each factor fulfilled the four interpretability criteria stressed by Hatcher [19:85-86]: 1) at least three variables with significant loadings on each retained factor, 2) variables loading on a given factor share some conceptual meaning, 3) variables loading on different factors appear to measure different constructs and, 4) the rotated factor pattern demonstrates simple structure, i.e. most variables load on only one factor and have near-zero loadings on others. Two variables, worry about being farmed, or robbed while high by one's peers and worry about police arrest, were dropped from the factor analysis, but univariate analysis showed that they both possessed high mean values, and were viewed as additional important risks to our sample.

Our results are limited in being based on a small nonprobabilistic sample which hinders generalization to other settings. However, we note that this analysis corresponds to previous studies $[13,14]$ indicating that for PWUID specific worry about HIV/AIDS exists alongside general living and security considerations.

Consideration of all these concerns echoes the classic paper by Strathdee et al. [22] that argued that "needle exchange is not enough", and that while vital, needle exchange programs should be, "... considered one component of a comprehensive programme including counselling, support and education". More than a decade later these words still ring true, with ethnographic [15] and survey - based [16] studies linking social instability (e.g. homelessness), to both heightened HIV risk behaviour and diminished adherence to anti-retroviral treatment therapy.

While certainly not detracting from the large number of rigorous studies indicating multiple positive HIV/AIDS related harm reduction effects associated with needle exchange programs (for a recent listing of these see [1:143]), our results again emphasize the need to address larger structural problems which form risks and worries for PWUID. Unfortunately in the present case the closure of the AVI-SOS fixed site needle exchange facility limits the organization's ability to address these broader programs. Throughout its existence the fixed-site provided a suite of services, ranging from providing hot meals through access to street nurses, referrals to housing/shelter organizations, personal counsellors and HIV/HCV testing to simply providing a safe, dry, warm place. With its closure AVI-SOS must attempt to provide these services via newly established outreach services which cannot individually offer the array of services provided by the now defunct fixed-site; which this analysis reveals their clientele want and need.

In conclusion, combined with the historically more frequently applied concept of risk, consideration and inclusion of PWUID's panoply of everyday worries into broader-based harm reduction interventions could provide important insights or "windows" into their lives and yield effective programs featuring the convergence of PWUID perspectives and public health goals.

\section{Competing interests}

The authors declare that they have no competing interests.

\section{Authors' contributions}

HE, EKG, JL, RS and EAR designed the study questionnaire, constructed the research design, collected the data upon which this analysis is based, and interpreted analysis results. LC, RS and EAR completed the statistical analysis, and wrote the manuscript draft. All authors read and approved the final manuscript.

\section{Acknowledgements}

We wish to particularly thank the participants of this study who gave their time and valuable information. We are also very grateful to AIDS Vancouver Island for their generous use of their facilities for interviewing and overall project support. Financial support was provided by an award from the Vancouver Foundation. EKG is supported by an IMPART Fellowship.

\section{References}

I. Institute of Medicine: Preventing HIV Infection among Injecting Drug Users in High-Risk Countries: An Assessment of the Evidence Washington: National Academies Press; 2007.

2. Aceijas C, Rhodes T: Global estimates of prevalence of HCV infection among injecting drug users. Inter J Drug Policy 2006, 18(5):352-358.

3. Canadian HIVIAIDS Legal Network: "Nothing about us without us". Greater, meaningful involvement of people who use illegal drugs: A public health, ethical and human rights imperative. 2006 [http://www.aidslaw.ca/publications/ publicationsdocEN.php? ref $=85$ ].

4. Des Jarlais D, Friedman S, Hopkins W: Risk reduction for the acquired immunodeficiency syndrome among intravenous drug users. Ann Internal Med 1985, 103:775-759.

5. Hagan H, Theile H, Weiss N, Hopkins S, Duchin J, Alexander E: Sharing of drug preparation equipment as a risk factor for Hepatitis C. Amer J Public Health 200I, 91 I:42-46.

6. Friedman S, Curtis R, Neaigus A, Jose B, Des Jarlais D: Social Networks, Drug Injectors' Lives, and HIVIAIDS New York, Kluwer Academic; 1999. 
7. Neaigus A, Freidman S, Kottiri B, Des Jarlais D: HIV risk networks and HIV transmission among injecting drug users. Evaluation and Program Planning 2001, 24:221-226.

8. Rhodes T, Simpson G, Crofts N, Ball A, Dehne K, Khodakevich I: Drug injecting, rapid HIV spread, and the "risk environment": Implications for assessment and response. AIDS 1999 , I 3(Supp A):S259-269.

9. Rhodes T, Singer M, Bourgois P, Friedman S, Strathdee S: The structural production of HIV risk among injecting drug users. Soc Sci Med 2005, 6 I: 1026-1044.

10. Smith K: Why are they worried? Concerns about HIVIAIDS in rural Malawi. Demographic Research, Special Collection 2003, I:277-3। 7

II. Smith K, Watkins SC: Perceptions of risk and strategies for prevention: Responses to HIVIAIDS in rural Malawi. Soc Sci Med 2005, 60:649-660.

12. Busza J: How does a "risk group" perceive risk? Voices of Vietname se sex workers in Cambodia. Journal of Psychology and Human Sexuality 2005, I 7( I-2):65-82.

13. Mizuno Y, Percell D, Borowski T, Knight K, the SUDIS Team: The life priorities of HIV-seropositive injection drug users: Findings from a community-based sample. AIDS and Behavior 2003 7(4):395-403.

14. Brogly S, Mercier C, Brunea C, Palepu A, Franco E: Towards more effective public health programming for injection drug users: Development and evaluation of the Injection Drug User Quality of Life Scale. Subst Use and Misuse 2003, 38(7):965-992.

15. Bourgois P: The moral economies of homeless heroin addicts: Confronting ethnography, HIV risk and everyday violence in San Francisco shooting encampments. Subst Use and Misuse 1999, 33:2323-235।.

16. Bouhnik A, Chesney M, Carrieri P, Gallais H, Morneau J, Moatti J-P, Obadia Y, Spire B, the MANIF 2000 Study Group: Nonadherence among HIV-infected injection drug users: The impact of social instability. J Acquired Immun Syndr 2002, 3I(Supp 3):SI49-SI53.

17. Wood E, Kerr T, Tyndall M, Montaner J: A review of barriers and facilitators of HIV treatment among injection drug users. AIDS 2008, 22: I247-I256.

18. Wood E, Tyndall M, Spittal P, Li K, Hogg R, Montaner J, O'Shaughnessey $M$, Schechter $M$ : Factors associated with persistent highrisk syringe sharing in the presence of an established needle exchange programme. AIDS 2002, I 6(6):94I-943.

19. Hatcher L: A Step-by-Step Approach to Using SAS for Factor Analysis and Structural Equation Modeling Cary, NC: SAS Press; 1994.

20. Costello A, Osborne J: Best practices in exploratory factor analysis: Four recommendations for getting the most from your analysis. Practical Assessment, Research Evaluation 2005 I0(7): I-9.

21. Loehlin J: Latent Variable Models: An Introduction to Factor, Path, and Structural Analyses Hillsdale, NJ: Lawrence Erlbaum Associates, Publishers; 1987.

22. Strathdee S, Patrick D, Currie S, Cornelisse P, Rekart M, Montaner J, Schechter M, O'Shaughnessy M: Needle exchange is not enough: Lessons from the Vancouver injection drug use study. AIDS I997, I I:F59-65.
Publish with Bio Med Central and every scientist can read your work free of charge

"BioMed Central will be the most significant development for disseminating the results of biomedical research in our lifetime. "

Sir Paul Nurse, Cancer Research UK

Your research papers will be:

- available free of charge to the entire biomedical community

- peer reviewed and published immediately upon acceptance

- cited in PubMed and archived on PubMed Central

- yours - you keep the copyright
BioMedcentral 